\title{
Cannula malposition during antegrade cerebral perfusion for aortic surgery: role of cerebral oximetry
}

\section{Mauvais positionnement de canule lors de perfusion cérébrale antérograde pour chirurgie aortique: rôle de l'oxymétrie cérébrale}

\author{
Simon K. C. Chan, MBBS • Malcolm J. Underwood, MD • \\ Anthony M.-H. Ho, MD • Jack M. So, RN • Adrienne K. Ho • \\ Innes Y. P. Wan, MBBS • Randolph H. L. Wong, MBBS
}

Received: 9 January 2014 / Accepted: 13 May 2014/Published online: 28 May 2014

(C) Canadian Anesthesiologists' Society 2014

\begin{abstract}
Purpose To describe the use of cerebral oximetry to detect a lack of right cerebral perfusion resulting from a malpositioned catheter used for antegrade cerebral perfusion during deep hypothermic circulatory arrest (DHCA). The simple corrective surgical adjustment that followed averted a potentially serious complication.
\end{abstract}

\begin{abstract}
Author contributions Simon K. C. Chan and Anthony M.-H. Ho managed the anesthesia and did most of the manuscript preparation. Malcolm J. Underwood, Innes Y.P. Wan, and Randolph H.L. Wong performed the surgery and gave important input during manuscript preparation. Adrienne K. Ho drew Fig. 1 and helped finalize Fig. 2. She also made important suggestions during manuscript preparation. Jack M. So was the perfusionist for the case and also gave important input during manuscript preparation.
\end{abstract}

S. K. C. Chan, MBBS

Department of Anaesthesia and Intensive Care, The Chinese

University of Hong Kong, Shatin, NT, Hong Kong SAR, China

M. J. Underwood, MD

Department of Surgery, The Chinese University of Hong Kong, Shatin, NT, Hong Kong SAR, China

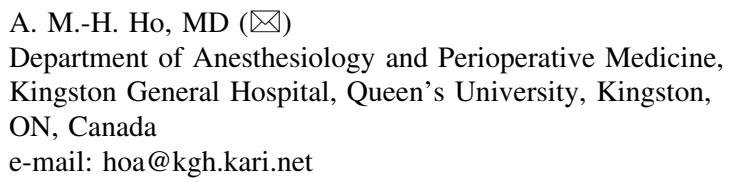

J. M. So, RN - I. Y. P. Wan, MBBS - R. H. L. Wong, MBBS Department of Surgery, Prince of Wales Hospital, Shatin, NT, Hong Kong SAR, China

\author{
A. K. Ho \\ Hull-York Medical School, York, UK
}

Clinical features A 57-yr-old male with a type-A aortic dissection undergoing DHCA required antegrade cerebral perfusion for cerebral protection. Catheters were placed accordingly in the left common carotid and brachiocephalic arteries. Whereas frontal cerebral oximetry immediately improved on the left, it did not improve on the right. It was immediately suspected that the tip of the brachiocephalic cannula had advanced into the right subclavian artery, thus depriving the right common carotid artery of blood flow. The problem resolved upon slight withdrawal of the cannula.

Conclusion Vigilance in anesthesia should not stop during DHCA or cardiopulmonary bypass. Cerebral oximetry may provide important information leading to actions that improve brain protection. Vigilances proved important in this case where the cannula tip used for antegrade cerebral perfusion was advanced too far into the right subclavian artery.

\section{Résumé}

Objectif Décrire l'utilisation de l'oxymétrie cérébrale dans la détection d'un défaut de perfusion cérébrale à droite suite à un mauvais positionnement d'un cathéter de perfusion cérébrale antérograde pour un arrêt circulatoire avec hypothermie profonde (DHCA). Le simple ajustement chirurgical qui a suivi pour corriger la situation a évité une complication potentiellement grave.

Caractéristiques cliniques Un patient, âgé de 57 ans, porteur d'une dissection aortique de type A nécessitant une DHCA, a reçu une perfusion cérébrale antérograde sélective pour la protection de son cerveau. Des cathéters ont donc été mis en place dans la carotide 
primitive gauche et dans le tronc brachiocéphalique. Alors que l'oxymétrie cérébrale frontale était immédiatement améliorée du côté gauche, elle ne s'est pas améliorée du côté droit. On a immédiatement soupçonné que l'extrémité de la canule brachiocéphalique avait avancé vers l'artère sous-clavière droite, privant ainsi l'artère carotide primitive droite de débit sanguin. Le problème a été résolu en tirant légèrement sur la canule.

Conclusion La vigilance au cours de l'anesthésie ne doit pas cesser au cours de la DHCA ou de la circulation extracorporelle. L'oxymétrie cérébrale peut fournir une information importante débouchant sur des actions qui améliorent la protection cérébrale. La vigilance s'est avérée importante dans ce cas où l'extrémité de la canule utilisée pour la perfusion cérébrale antérograde était trop avancée dans l'artère sous-clavière droite.

Circulatory arrest to ensure a bloodless and motionless surgical field is required during repair or replacement of the distal ascending aorta or aortic arch. The strategies for brain protection during this critical period when blood flow to the brain is absent include moderate to deep hypothermic circulatory arrest (DHCA) using cardiopulmonary bypass

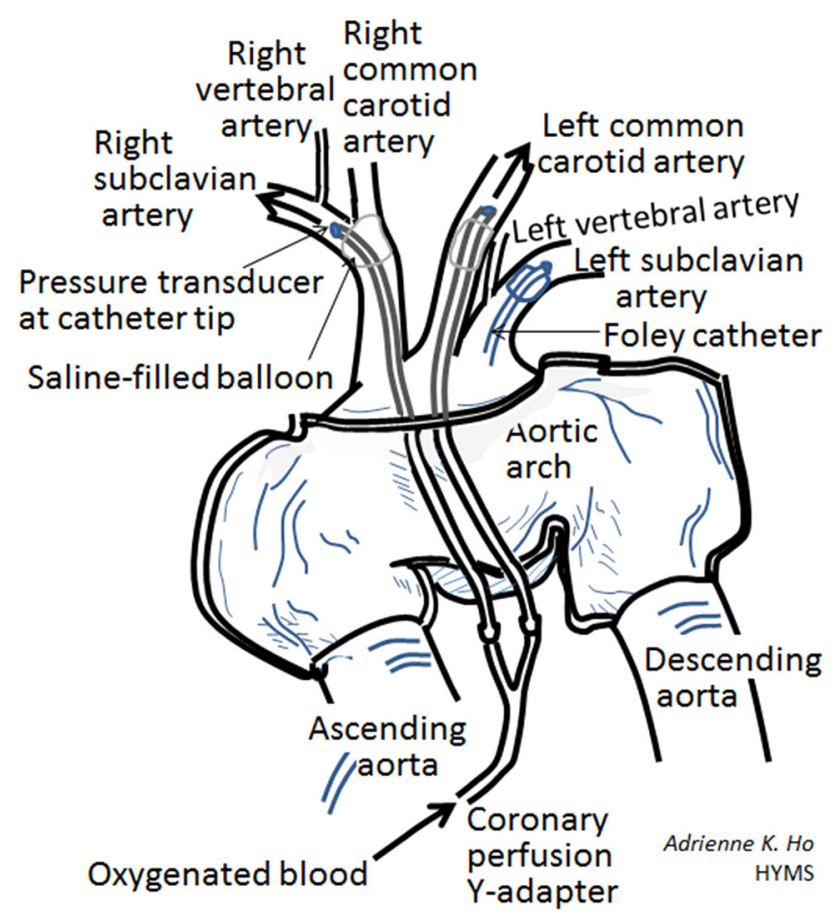

Fig. 1 A malpositioned catheter used in antegrade cerebral perfusion resulted in non-perfusion of the right common carotid artery (adapted from http://www.mac-conference.com/xconfig/upload/files/Vascutek\% 20_3\%20Thoraflex\%20Hybrid_Shrestha\%281\%29.pdf [accessed October 25, 2013])
$(\mathrm{CPB})^{1}$ and use of drugs to reduce the cerebral bispectal index (BIS) to zero. ${ }^{2}$ At $18-24^{\circ} \mathrm{C}$ and with much of the patient's upper head packed in ice, the incidence of serious postoperative permanent brain dysfunction is low if circulatory arrest is $<30 \mathrm{~min}^{3,4}$ Use of antegrade cerebral perfusion (Fig. 1) may allow for longer durations of circulatory arrest, allow a milder degree of hypothermia, obviate the need for circulatory arrest, and reduce the incidence and severity of postoperative brain dysfunction. $^{3-5}$ An alternative is retrograde cerebral perfusion via the superior vena cava or even integrated antegrade and retrograde cerebral perfusion. ${ }^{3}$ Neither cerebral perfusion technique is clearly superior and the choice depends on surgical preference and circumstances. ${ }^{3}$

Regional cerebral oxygen saturation $\left(\mathrm{rSO}_{2}\right)$ monitoring has emerged as an important technique for surgery involving the distal ascending aorta and aortic arch. ${ }^{6} \mathrm{We}$ herein report a case in which use of $\mathrm{rSO}_{2}$ not only signalled the need to provide cerebral perfusion after a period of circulatory arrest, but also allowed the immediate detection of a malpositioned cannula used for antegrade cerebral protection that failed to perfuse the right common carotid artery as intended.

\section{Case report}

The patient gave signed consent for publication of this report.

A 57-yr-old, 90-kg, 166-cm male was diagnosed with a chronic type-A aortic dissecting aneurysm (measuring $4.8 \mathrm{~cm}$ at the ascending aorta) involving the brachiocephalic trunk, left common carotid artery, and left subclavian artery. The patient underwent aortic arch repair with $\mathrm{CPB}$ using femoral artery and double-stage inferior vena cava cannulae, a left ventricular vent via the right superior pulmonary vein, and DHCA. Intraoperative monitors included bilateral radial arterial cannulae, a right internal jugular central venous cannula, bilateral frontal $\mathrm{rSO}_{2}$ (INVOS ${ }^{\mathrm{TM}}$, Covidien, Troy, MI, USA), BIS, plus the routine monitors ${ }^{7}$ for major cardiac surgery.

Induction of anesthesia was uneventful. Ice was packed around the patient's head soon after CPB was started. Deep hypothermic cardiac arrest was carried out by cooling the patient to $18^{\circ} \mathrm{C}$ rectally. Thiopentone $500 \mathrm{mg}$ was given prior to stopping the CPB pump, ${ }^{2}$ immediately achieving a BIS reading of 0 . A timer was started at the onset of DHCA, whereupon the aorta was divided and cold blood cardioplegia was administered. Surgical repair started with the aortic arch divided between the innominate artery and just distal to the left subclavian artery.

After almost $30 \mathrm{~min}$ of DHCA and aortic repair, bilateral $\mathrm{rSO}_{2}$ fell $20 \%$ below baseline and completion of the operation 


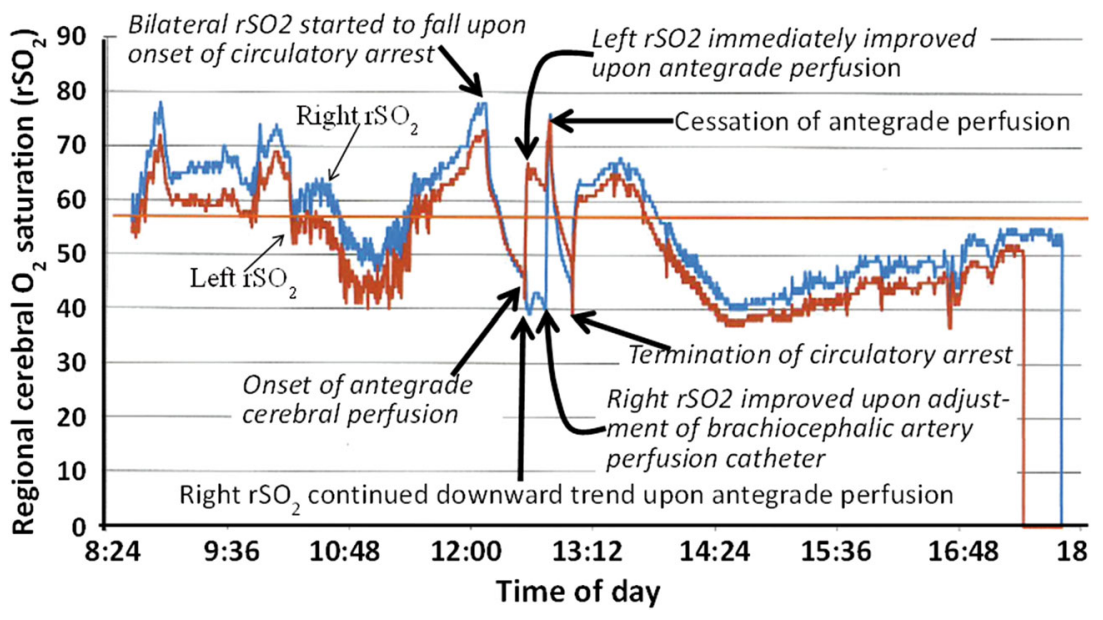

Fig. 2 Timeline of bilateral cerebral oximetry $\left(\mathrm{rSO}_{2}\right)$ monitoring. Baseline $\mathrm{rSO}_{2}$ was $57 \%$ before induction of anesthesia (horizontal blue line with red line superimposed). Bilateral $\mathrm{rSO}_{2}$ dropped below baseline upon the first initiation of cardiopulmonary bypass (CPB; before cross-clamping the ascending aorta with retrograde perfusion via femoral and right atrial lines) at around 10:40 when systemic

was not imminent. Antegrade cerebral perfusion was started using two 14-Fr cannulae with saline-filled balloon tips (Fig. 1) with an independent roller pump to maintain an oxygenated blood flow of $10-12 \mathrm{~mL} \cdot \mathrm{kg}^{-1} \cdot \mathrm{min}^{-1}$ (maximum $1,200 \mathrm{~mL} \cdot \mathrm{min}^{-1}$ ) and balloon tip pressure of $30-40 \mathrm{mmHg} .{ }^{5}$ The left subclavian artery was occluded with a 10-Fr Foley catheter to prevent a "steal" caused by blood flowing into the arm via the left vertebral artery. The left $\mathrm{rSO}_{2}$ quickly recovered but, unexpectedly, the right $\mathrm{rSO}_{2}$ did not (Fig. 2). The right radial blood pressure increased from $\sim 20 \mathrm{mmHg}$ to $\sim 90-100 \mathrm{mmHg}$ while the left radial pressure stayed at $\sim 20 \mathrm{mmHg}$. The unresponsive right $\mathrm{rSO}_{2}$ plus the excessive increase in right radial pressure suggested that the tip of the right catheter used for cerebral perfusion might have been placed within the right subclavian artery (Fig. 1). The surgeons pulled back the catheter slightly and the $\mathrm{rSO}_{2}$ quickly recovered (Fig. 2).

Total circulatory arrest time was $76 \mathrm{~min}$. Surgery and anesthesia were otherwise completed uneventfully. The postoperative course was complicated by difficulties weaning the patient from the ventilator. The patient's trachea was extubated four days after surgery, and he was transferred the following day to a high-dependency unit where he stayed for one day. He was discharged home two weeks later. Postoperatively, the patient did not have any gross neurologic deficit, delirium, or seizures.

\section{Discussion}

In this patient, the combination of a drop in $\mathrm{rSO}_{2}$ in the right frontal lobe and normal $\mathrm{rSO}_{2}$ in the left frontal lobe was a blood pressure dipped and lung ventilation stopped with inflow of venous admixture via the heart. The $\mathrm{rSO}_{2}$ improved when the ascending aorta was cross-clamped at about 11:20. Bilateral $\mathrm{rSO}_{2}$ also dropped below baseline upon re-initiation of $\mathrm{CPB}$ after circulatory arrest at 13:50, possibly due to rewarming of the brain and hypotension, as requested by surgeons in view of bleeding

crucial event pointing to malpositioning of the catheter used in right antegrade cerebral perfusion. Other monitoring parameters of concern were the unusually high pressure at the catheter tip (Fig. 1), suggesting it may be abutting a vessel wall, and the higher than expected right radial pressure due to unexpectedly high flow. Since the BIS reading was already at 0 , it would not have been able to detect any unilateral perfusion deficit. If the problem had not been detected (which would have been the case if cerebral oximetry had not been used or if the anesthesiologists had not noticed the non-recovering $\mathrm{rSO}_{2}$ tracing), perfusion of the right brain would likely have been compromised during prolonged DHCA. The unilateral failure of the $\mathrm{rSO}_{2}$ to recover suggested that the poor $\mathrm{rSO}_{2}$ was not the result of skin ischemia or vasopressors. ${ }^{89}$

At our institution, we routinely place bilateral radial arterial monitors in patients undergoing aortic arch surgery. Even without $\mathrm{rSO}_{2}$, it is conceivable that the high right radial pressure alone would have alerted the team to a malpositioned cannula. Nevertheless, the reliability of using the right radial arterial pressure alone in detecting such malpositioning is unknown. We prefer to cannulate the innominate artery rather than the right common carotid artery for several reasons: it is more difficult to cannulate the deeper carotid artery; vessels closer to the cranium are more fragile and harder to repair if a tear should occur; cannulation of the innominate artery allows perfusion of the right vertebral artery and right arm. An unexpected low right radial pressure would result if the right common carotid artery was inadvertently cannulated. ${ }^{10}$

Malpositioning of the catheter used in antegrade cerebral perfusion is not rare. In 35 consecutive patients 
with aortic arch aneurysm undergoing total arch replacement or transaortic stent graft implantation, a drop in $\mathrm{rSO}_{2}$ led to the detection of four cases requiring the antegrade perfusion catheter to be withdrawn slightly (as in our case) or replaced. ${ }^{10}$ Not surprisingly, $\mathrm{rSO}_{2}$ failed to detect an accidental entry of the catheter into the right common carotid artery, which was detected by transesophageal echocardiography. ${ }^{10}$

Unilateral cerebral desaturation during aortic arch surgery that is unrelated to catheter malpositioning during antegrade perfusion can also occur. Agostini et al. ${ }^{11}$ described a case of type-A aortic dissection repair. Cardiopulmonary bypass was performed with a right axillary artery side graft for arterial inflow. An abrupt drop in the right $\mathrm{rSO}_{2}$ to $15 \%$ occurred upon initiation of $\mathrm{CPB}$, while the left $\mathrm{rSO}_{2}$ decreased to $40-50 \%$. An expansion of the false aortic lumen along the right epiaortic vessels was suspected. To improve perfusion through the true lumen, a second side graft was then added to increase arterial inflow for CPB. Bilateral $\mathrm{rSO}_{2}$ gradually returned to baseline. The patient was discharged 12 days postoperatively without apparent neurologic deficit. Janelle et al. ${ }^{12}$ reported a case of ruptured DeBakey type-1 aortic dissection. During aortic valve replacement, an abrupt profound drop in right $\mathrm{rSO}_{2}$ was observed, which led to immediate temporary suspension of the valve replacement and immediate initiation of circulatory arrest. A false lumen was found extending from the ascending aorta through the right innominate artery into the right common carotid artery. The arch was repaired under retrograde cerebral perfusion, during which no improvement in right $\mathrm{rSO}_{2}$ was observed while the left $\mathrm{rSO}_{2}$ continued to decrease. Bilateral $\mathrm{rSO}_{2}$ improved after the arch repair and re-institution of antegrade CPB via cannulation of the ascending aortic graft. Wang et al. ${ }^{13}$ found a sudden drop in $\mathrm{rSO}_{2}$ from $51 \%$ to $34 \%$ while the sternum was being rewired after total arch replacement with the elephant trunk technique. Immediate reopening of the sternum led to the discovery of colour change in the innominate artery distal to the anastomosis of the aortoinnominate vascular graft, suggesting acute dissection likely due to clamp injury. Immediate repair was carried out and the patient recovered.

Incompleteness of the Circle of Willis due to missing anterior $(22 \%)$ or left posterior $(46 \%)$ communicating arteries occurs in $20-30 \%$ of the population, ${ }^{14}$ which might explain why, in our case and in the cases ${ }^{10-13}$ cited above, flow from the left cerebral circulation was insufficient in perfusing the right side. In some of our other cases, perfusion of the left common carotid artery alone led to improvement in both left and right $\mathrm{rSO}_{2}$, thus increasing bilateral brain protection with only left common carotid perfusion (for better exposure) while arch repair was underway. In a series of 13 cases with bilateral $\mathrm{rSO}_{2}$ monitoring, Harrer et al. ${ }^{15}$ found that 12 patients required bilateral antegrade cerebral perfusion instead of just left common carotid artery antegrade cerebral perfusion. A systematic review of the literature led Zheng et al. ${ }^{16}$ to conclude that reductions in $\mathrm{rSO}_{2}$ during cardiac surgery may provide an indication of mechanical mishaps related to CPB cannulae, particularly during aortic surgery.

To calculate $\mathrm{rSO}_{2}$, cerebral oximetry transcutaneously measures differences in pulsed near-infrared light absorption between oxygenated and deoxygenated hemoglobin in the frontal lobes of the cerebral cortex. ${ }^{16}$ The probes are optimally placed on both sides of the patient's forehead cephalad enough not to overlie the frontal sinuses. The regional saturation index, derived from venous blood (70-75\%) and arterial blood (25-30\%), reflects oxygen consumption and delivery, respectively. Cerebral oximetry is often considered a "first alert" monitor for reduced cerebral perfusion due to shock, interruption of carotid supply, hyperventilation, and poor blood oxygenation. A drop in the $\mathrm{rSO}_{2}$ indicates decreased arterial oxygen supply and/or increased oxygen extraction, suggesting increased ischemic risk. Unlike pulse oximetry, cerebral oximetry does not require blood pulsatility.

Using a decrease in cerebral oximetry of $>25 \%$ from baseline as an indicator of increased ischemic risk, Murkin et $a l .^{17,18}$ made corrective measures that included augmentation of oxygen delivery and reduction in brain oxygen consumption (e.g., increased blood pressure; blood transfusion; adjustments in ventilation, head and neck position, acid-base, and temperature; and increased depth of anesthesia) and achieved reduced major organ morbidity and length of hospital stay in monitored patients undergoing cardiac surgery. ${ }^{17,18}$ Deschamps et al. ${ }^{19}$ found $\mathrm{rSO}_{2}$ desaturation occurring in $49 \%$ of the patients in high-risk or complex cardiac surgery. This was reversed by repositioning the patient's head, and optimization of oxygen delivery to the brain was achieved in $88.2 \%$ of cases. Fischer et al. ${ }^{6}$ found that patients whose $\mathrm{rSO}_{2}$ was under the absolute threshold of $60 \%$ for more than $30 \mathrm{~min}$ while undergoing aortic arch repair had an extended hospital stay of four days. In a patient with Raynaud's phenomenon, a bilateral drop in $\mathrm{rSO}_{2}$ with concomitant loss of finger pulse oximetry was reversed with intravenous nitroglycerin after separation from CPB. ${ }^{20}$

Likewise, other authors have shown that optimization of $\mathrm{rSO}_{2}$ may help prevent hypoxic brain injury and reduce length of hospital stay in higher risk patients undergoing major abdominal surgery. ${ }^{21}$ Reduction in $\mathrm{rSO}_{2}$ also predicts postoperative cognitive dysfunction in thoracic surgery $^{22}$ and is a reliable indicator of clamping ischemia in carotid endarterectomy. ${ }^{23}$

In conclusion, we have presented a case to remind anesthesiologists that vigilance should not stop during 
DHCA or cardiopulmonary bypass. In fact, cerebral desaturation is common, with a reported incidence of up to $50 \%$ during $\mathrm{CPB} .{ }^{19}$ In our case, bilateral cerebral oximetry indicated a decrease in cerebral perfusion as $\mathrm{rSO}_{2}$ had fallen $20 \%$ below baseline 30 min after initiation of circulatory arrest. It also alerted the team that a cannula tip for antegrade cerebral perfusion had been misplaced too far into the right subclavian artery. Further studies are required for a more precise calculation of the benefits and costeffectiveness of routine cerebral oximetry in type-A aortic dissection surgery.

Conflicts of interest None declared.

\section{References}

1. Tsai JY, Pan W, Lemaire SA, et al. Moderate hypothermia during aortic arch surgery is associated with reduced risk of early mortality. J Thorac Cardiovasc Surg 2013; 146: 662-7.

2. Al-Hashimi S, Zaman M, Waterworth P, Bilal H. Does the use of thiopental provide added cerebral protection during deep hypothermic circulatory arrest? Inter Cardiovasc Thorac Surg 2013; 17: 392-7.

3. Lee TY, Safi HJ, Estrera AL. Cerebral perfusion in aortic arch surgery Antegrade, retrograde, or both? Texas Heart Inst J 2011; 38: 674-7.

4. Okita Y, Okada K, Omura A, et al. Total arch replacement using antegrade cerebral perfusion. J Thorac Cardiovasc Surg 2013; 145: S63-71.

5. Okita Y, Okada K, Omura A, et al. Surgical techniques of total arch replacement using selective antegrade cerebral perfusion. Ann Cardiothorac Surg 2013; 2: 222-8.

6. Fischer GW, Lin HM, Krol M, et al. Noninvasive cerebral oxygenation may predict outcome in patients undergoing aortic arch surgery. J Thorac Cardiovasc Surg 2011; 141: 815-21.

7. Merchant $R$, Chartrand D, Dain $S$, et al. Guidelines to the practice of anesthesia - Revised edition 2014. Can J Anesth 2014; 61: 46-71.

8. Davie SN, Grocott HP. Impact of extracranial contamination on regional cerebral oxygen saturation: a comparison of three cerebral oximetry technologies. Anesthesiology 2012; 116: 834-40.

9. Meng L, Cannesson M, Alexander BS, et al. Effect of phenylephrine and ephedrine bolus treatment on cerebral oxygenation in anaesthetized patients. Br J Anaesth 2011; 107: 209-17.
10. Orihashi $K$, Sueda T, Okada K, Imai K. Malposition of selective cerebral perfusion catheter is not a rare event. Eur J Cardiothorac Surg 2005; 27: 644-8.

11. Agostini M, Di Gregorio V, Bertora M, Avallato C, Locatelli A. Near-infrared spectroscopy-detected cerebral ischemia resolved by cannulation of an axillo-femoral graft during surgical repair of type A aortic dissection. Heart Surg Forum 2012; 15: E221-3.

12. Janelle GM, Mnookin S, Gravenstein N, Martin TD, Urdaneta F. Unilateral cerebral oxygen desaturation during emergent repair of a DeBakey type 1 aortic dissection: potential aversion of a major catastrophe. Anesthesiology 2002; 96: 1263-5.

13. Wang SC, Lo PH, Shen JL, et al. Innominate artery dissection with presentation of sudden right frontal desaturation detected by cerebral oximetry in complicated thoracic aortic aneurysm repair surgery: a case report. J Clin Anesth 2011; 23: 137-41.

14. Merkkola $P$, Tulla $H$, Ronkainen A, et al. Incomplete circle of Willis and right axillary artery perfusion. Ann Thorac Surg 2006; 82: 74-9.

15. Harrer $M$, Waldenberger FR, Weiss $G$, et al. Aortic arch surgery using bilateral antegrade selective cerebral perfusion in combination with near-infrared spectroscopy. Eur J Cardiothorac Surg 2010; 38: 561-7.

16. Zheng $F$, Sheinberg $R$, Yee MS, Ono M, Zheng $Y$, Hogue $C W$. Cerebral near-infrared spectroscopy monitoring and neurologic outcomes in adult cardiac surgery patients: a systematic review. Anesth Analg 2013; 116: 663-76.

17. Murkin JM, Adams SJ, Pardy E, Quantz M, McKenzie FN, Guo L. Monitoring brain oxygen saturation during coronary bypass surgery improves outcomes in diabetic patients: a post hoc analysis. Heart Surg Forum 2011; 14: E1-6.

18. Murkin JM, Adams SJ, Novick RJ, et al. Monitoring brain oxygen saturation during coronary bypass surgery: a randomized, prospective study. Anesth Analg 2007; 104: 51-8.

19. Deschamps A, Lambert J, Couture P, et al. Reversal of decreases in cerebral saturation in high-risk cardiac surgery. J Cardiothorac Vasc Anesth 2013; 27: 1260-6.

20. Aron JH, Fink GW, Swartz MF, et al. Cerebral oxygen desaturation after cardiopulmonary bypass in a patient with Raynaud's phenomenon detected by near-infrared cerebral oximetry. Anesth Analg 2007; 104: 1034-6.

21. Casati A, Fanelli G, Pietropaoli P, et al. Continuous monitoring of cerebral oxygen saturation in elderly patients undergoing major abdominal surgery minimizes brain exposure to potential hypoxia. Anesth Analg 2005; 101: 740-7.

22. Tang L, Kazan R, Taddei R, Zaouter C, Cyr S, Hemmerling TM. Reduced cerebral oxygen saturation during thoracic surgery predicts early postoperative cognitive dysfunction. Br J Anaesth 2012; 108: 623-9.

23. Pedrini L, Magnoni $F$, Sensi $L$, et al. Is near-infrared spectroscopy a reliable method to evaluate clamping ischemia during carotid surgery? Stroke Res Treat 2012; 2012: 156975. 